\title{
IS IT STILL INDUSTRY? TOWARDS A NEW LOOK AT ERIKSON'S RELEVANCE TO SCHOOL AGE YOUTH WITH IMPLICATIONS FOR PRACTICE
}

\author{
Karen VanderVen \\ Department of Psychology in Education, University of Pittsburgh
}

Step into an urban after-school program. In one area, two youngsters are busily constructing a robot with Legos, with printed instructions laid out in front of them. In a corner, three giggling girls are glancing at another girl, who looks uncertainly around her. They focus on a knot of boys who are nudging each other and continue giggling. A boy tries to join the Lego group, but soon turns away. He wanders into the gymnasium where a basketball game is just being organized. In the homework corner, several youngsters grumble as they open their math textbooks and take out their worksheets under the watchful eye of a staff member.

The vignette above contains a hint of the complex issues and behaviors characterizing school age youth today. Much has changed since the post-World War II years in which Erikson wrote, including the development of after school programs. In 1950, in his famous book, Childhood and Society (1950), Erik Erikson proposed his eight stages of development, suggesting that the positive outcome for successfully negotiating the school age years was to develop a sense of industry: With the oncoming latency period, the normally advanced child ... now learns to win recognition by producing things . . . he comes ready to apply himself to given skills and tasks . . . He develops industry - that is, he adjusts himself to the inorganic laws of the tool world. He can become an eager and absorbed unit of a productive situation ... The work principle (Ives Hendrick) teaches him the pleasure of work completion by steady attention and persevering diligence.

His danger, at this stage, lies in a sense of inadequacy and inferiority. If he despairs of his tools and skills or of his status among his tool partners ... he abandons hope for the ability to identify early with others who apply themselves to the tool world ... and considers himself doomed to mediocrity . . . Many a child's development is disrupted when family life may not have prepared him for school life or when school life may fail to sustain the promises of the early stages (226-227).

This is the negative resolution of the "psychosocial crisis" (1050) or "antipathic counterpart" (Erikson, 1982, p. 64). With Erikson's primary description of the psychological tasks of the school years reviewed, one can ask, "How would this apply today?"

The purpose of this paper, therefore, is to reexamine Erikson's concept of development during the school years and of changes in social context and advances in developmental theory that inform and shape the new formulations. A special attempt is made to situate and reinterpret them as closely as possible in an Eriksonian conceptual framework - in other words, applying Erikson to himself as much as possible. 
The paper includes the following:

- Citation of key changes in society that particularly impact school age children

- Review of advances in knowledge of development and theoretical conceptualizations of the life course

- Description of some key features of a contemporary life course theory that will characterize the reformulation of Erikson's original description of the school-age years

- Presentation of a proposed new model of development in the school-age years in an Eriksonian vein

- Implications of the new theory for current practice issues

\section{Trends in Society and Developmental Theory}

\section{Societal Trends}

Eriksonian theory established solidly the power of sociocultural context in shaping the process and content of development. Thus if this context has changed, and there is no doubt that it has - radically - then in a transactional way changes must be made to Eriksonian theory to reflect these changes. Given that, Erikson's initial eight stages of human development were situated in the post-World War II context of the late 1940s and early 1950s. To optimally consider any application of Erikson today, one must consider that the practices and values of society have changed.

With some danger of oversimplification, there are salient characteristics of society today that have exerted a powerful influence on child and youth development since Erikson's proposals and today might be deemed particularly relevant to understanding the school-age years (VanderVen, 1996).

Many of them concern the nature of the activities that occupy school-age children, which could affect the degree to which youngsters develop the tool skills described in the following section by Erikson.

\section{Characteristics of Society}

Technology. The advent of technology has had a transformational effect on child and youth development. Computers, cell phones, email, search engines, video games, and social networking sites - are all used, often quite competently, by today's tech-savvy school-age children. However, despite the emergence of potentially developmentally adaptive activity afforded by these technological advances, such as interactive games and online collaborative learning environments, there are forces that mitigate making optimal use of them. These will be addressed later in this article. 
Over-scheduling. Eccles et al. (2006) counter an earlier contention that children are harmed by participation in too many adult-directed, structured activities because they do not have time for relaxation and independent play and exploration. Actually, overscheduling is a social-class related phenomenon, where it is much more applicable to upper-class children. Lower-class children are much less likely to have access to these kinds of activities, to their detriment (Lareau, 2003). However, when taken to the extreme, as it often is in sports, overscheduling can have negative effects such as stress.

Premature maturity. This concept suggests that the standards of maturity, in terms of worldliness, sexual interest, and teenage clothing-most particularly for girls - is steadily creeping downwards from adolescence into the elementary school-age years. Among a host of other dangers that accompany a sense that children should dress, think, and act older than their age, one vital concern is that these improperly advanced interests deter girls from developing the skills and activity involvements that formerly characterized the elementary school years and indeed Erikson's stage of industry.

The self-esteem movement. This is "defined by how much value people place on themselves" (Baumeister et al., 2002, p. 2). Perhaps misinterpreted, but certainly misapplied, the pressure to ensure that children always feel good about themselves that took place in the 1980s, like so many other well-intentioned movements, came to have unanticipated — and damaging - results. These include diminished motivation and decreased care in work habits. Ironically, and sadly, there is evidence that this overemphasis on self-esteem has led to a possible decrease in real self-esteem, when that is defined as real achievement acknowledged by others (e.g., VanderVen, 2008).

Decline of neighborhood safety. In the past, youngsters in most neighborhoods could safely roam about, with adults informally watching out for them and with bullying from others perhaps occurring but not as intensely as it does today. Increase of gang behavior and unsafe neighborhoods, particularly in urban centers but also in suburbia, are a pressing issue today and represent a real threat to optimal development in childhood.

Emergence of after-school programming as a societal institution. In 1950, afterschool formal programs were almost unheard of. Youngsters would typically go home after school and go out and play. There was much less formally organized activity than there is today for the segment of the population of children (upper middle- and upper-class) who now more consistently receive such activities. Access to the kinds of activities that contribute to acquisition of both academic and life skills during the school-age years is more limited for lower-class children whose families' life styles and incomes do not always enable these opportunities (e.g., Lareau, 2003). Due in part to the increased number of mothers into the workforce, after school programs have become one of the fastest growing forms of children's services today. 
Elimination of recess, music, physical education, and the creative arts in many schools. Both budgetary problems and changes in values and practices in schooling have resulted in greater attention to — indeed, a near exclusive-focus on basic academic instruction. These practices fly in the face of recognizing such contributors to learning as social skills, engagement, physical fitness, and the opportunity to be exposed to areas in which one might discover a special talent. For those children for whom academic learning, for whatever reason, is a challenge, developing and having others recognize nonacademic areas of strength is crucial for their positive development. Furthermore, where the school does not offer a varied palette of activities, singular emphasis on core subject knowledge may serve to decrease motivation to learn, in that the children simply will not like school or enjoy going to school.

Changes in family structures. The decline of the stable nuclear family is welldocumented. Today there are numerous family structures: single-parent households, same-sex parents, and so forth. A much greater percentage of women are employed full time outside the home than were in 1950. In part as a response to these changes, interventions for children are much more family centered and focused on the total environment of children, that is, a holistic or ecological approach as pioneered by Urie Bronfenbrenner (1977), with his famous concept of embedded systems that contain and influence the development of children.

Increase in social and emotional problems in childhood settings. Behavioral problems seem to be on the increase, ranging from bullying to attention deficit disorder, to resistance to adult authority. In particular, bullying - ranging from teasing to excluding to violent behavior-is a profound concern today to the extent its origins, as well as manifestations, are not yet fully understood, and in the case of the consequences for bullies and their victims, can be severe.

\section{Trends in Developmental Psychology}

In developmental psychology, many changes, conceptual and empirical, have occurred since 1950 that advance our understanding of both theoretical approaches to child development and the actual nature of the developmental process. While all of these cannot be reviewed or covered here, the following are the most salient.

Decline of psychoanalytic theory. Erikson was a psychoanalyst primarily, and his theory moved psychoanalytic theory to new levels of comprehensiveness and relevance. Subsequent to the high value of psychoanalytic theory in the 1950s, an influx of new ways of approaching development emerged, including behaviorism, positive psychology, social cognition, and postmodernism. Incorporating aspects of more recent theories holds the promise of enriching and making Eriksonian theory more applicable while still remaining faithful to its psychoanalytic roots.

Nonlinear dynamical systems theory. Nonlinear dynamical systems theory, concerned with interconnectedness, unpredictability, and disequilibrium in systems, has been applied to development and developmental concepts, and has rapidly 
transformed thinking about it. Indeed, that is in great contrast to the premise that "Models of developmental change assume an orderly, sequential, and predetermined unfolding of psychological functions and structures" (Galatzer-Levy, 2004, p. 419). Analyses of applications specific to Erikson have been done by GalatzerLevy (2003) and VanderVen (2005). According to the former, Erikson proposed a "basic psychoanalytic model, [with] the assumption of developmental sequences with development described as occurring in an orderly series of steps roughly tied to a person's age" (p. 421). However, "Nonlinear dynamics suggest that development can occur by other means than epigenetic unfolding of predetermined developmental lines" (p. 423). Another interpretation of epigenesis and Erikson's life cycle theory suggests that development is more nonlinear and complex than is commonly thought. But in the sense of nonlinear dynamical systems theory, as it is considered in-depth by Galatzer-Levy, Erikson's formulation is not sufficiently complex, given current understanding of both the theory and of the developmental process.

Resilience and positive psychology. Emerging from the emphasis on pathology that once dominated developmental psychology and was encouraged by psychoanalysis is a focus on the qualities that make children thrive even in the face of adversity. This perspective focuses more on strengths and how difficulties help youngsters develop positive strategies for dealing with difficulties. Recent work on developmental assets reflects this approach. Developmental assets are those ingredients or "building blocks for success, both in the external environment and internal developmental processes that contribute to making a young person psychologically strong" (e.g., Scales, Sesma \& Bolstrom, 2004; VanderVen, 2008). Among recognized indicators of resilience are involvement in activities, hobbies, and positive attention from nonfamilial adults (Werner \& Smith, 1992). There are many other strengths highlighted within the study of positive youth development, such as optimism, autonomy, and the presence of social support. However, not all positive psychological notions are associated with positive development under all circumstances. As discussed earlier, an overemphasis on self-esteem can lead to undesirable outcomes. Positive self-esteem comes from accomplishment over time that is deserving of respect from others.

\section{Change and Stability in Eriksonian Theory}

Subsequent to Erikson's proposal for the eight stages of development, numerous scholars of the life cycle proposed some new ways of viewing it. Perhaps the most evident among these changes is that the name has changed from life cycle to life span to the current life course. Two conditions are needed to make Erikson relevant today:

1. Recognizing that his work has often been misinterpreted in a simplistic way, meaning that certain critiques may not really apply. For example, Erikson's original life cycle theory has too often been rigidly tied into 
"stages" and their associated developmental outcomes too tightly bound. A careful reading of Erikson shows that these criticisms are inappropriate. He describes how a succeeding stage unfolds and emerges from the previous ones, and that such qualities as identity not only begin earlier than adolescence, but also may remerge later on in life. Indeed, it is true that Eriksonian life cycle theory can be interpreted as more complex and dynamic than these reductionist interpretations even though, as just described, it as not as complex as suggested by current nonlinear dynamical systems theory applied to development.

2. To revise or adapt Eriksonian theory in such a way that the result, paradoxically, reflects necessary changes to make it fit better to these contemporary conditions while incorporating as much as possible the many Eriksonian ideas and concepts that are almost timeless in their relevance. In a sense we do not want to throw the baby out with the bath water.

\section{Implications for Theory Revision and Modification}

There are numerous implications of the above considerations that properly integrated would entail the formulation of an overhauled, if not entirely new, Erikson-inspired theory of development in the school-age years. While these implications are not all enumerated here, some of the most important among them include the following:

- Greater emphasis or inclusion of needs for safety, both emotional and physical

- Need for greater adult attentiveness in general and monitoring of children's activities, including advocating for health activities that have been downsized in recent years and assuring that violent, aggressive, and exclusionary behavior is addressed

- Focus on providing the activities of childhood that expose youngsters both to the intergenerationally and peer transmitted culture of childhood and to the authentic and authoritative domains that nurture academic skills and interests, engagement, knowledge, and identifiable, useful skills

- Inclusion of ways of providing appropriate adult caring and empathic emotional support

\section{Basic Features of a New Model}

The new model for Erikson's Stage of Industry vs. Inferiority will contain the following features:

Phases rather than stages of development. Throughout his writings, Erikson refers to stages of development, and he is generally referred to as a stage theorist. However, Levine (1989), in her review of adult development theories, considers Erikson's 
to be a phase theory. According to Levine, a phase theory focuses on "the major life tasks or conflicts that stimulate growth. These tasks or conflicts emerge at relatively specific times in the life cycle. The way we accomplish or resolve them continues to influence us for the rest of our lives" (p. 61). This concept is more akin to what most developmentalists feel are stage theories. Combining Levine's thinking and the more recent perspective that development is less defined by a specific theme tightly linked to a specific age, the term phase reflects the inexact boundaries of the beginning and termination be associated with the general age range.

Themes of development not bounded by stages. A theme is a developmental feature or task that can be associated with a particular phase, but may be associated with others and is not rigidly bounded in concept. For example, identity is not a singular concept. It has been described in extensive literature as having many different types, manifestations, and forms of presence across the entire life course.

Greater complexity of the developmental process-non-linear and recursive aspects. This is concerned with the notion that one major developmental theme, even if it contains all aspects of those that preceded it, is too simplistic and that modern insights into nonlinear dynamical systems theory encourage a multicomponent picture. Nonlinear dynamical systems theory, also known as chaos or complexity theory, has been applied to human development for many years. As to Erikson, on one hand (as stated earlier) his theory does not propose the invariant, rigid progression of age related stages many who misread him claim it to be. On the other hand, his theory does not incorporate the degree of complexity necessary to fully explain such an inherently complex phenomenon as human development.

Viewing stage related themes as universals throughout the human life course. Erikson's universal themes of development, for example, trust, autonomy, initiative, industry, identity, and generativity, are present in all recognized phases of development to a more or less salient degree-as, often little recognized by others, which was acknowledged by Erikson. If some (erroneously) consider Erikson's theory horizontal with its stages, they can also be considered vertical—a common theme throughout the life course, although manifesting itself in different ways at various ages. Anna Freud's concept of "Developmental Lines" (1965) stressing how important developmental themes evolve over time to greater maturity, comes to mind. Combining the notion of developmental lines with Erikson's age-related themes could have great promise in that it would enable a more graphic and obvious representation of Erikson's own recognition that these universals are present in various manifestations throughout life, taking a more organizing stance at one particular age range.

Dimensions rather than dichotomies. Development is so complex that viewing any attribute as located at one or the other pole of a dichotomy is not an accurate representation. We are on safer ground if we consider any theme or characteristic as distributed along a dimension of more or less rather than absolutely present or absent. The concept of "masculinity" and "femininity" are good examples. 
Multiple themes with varied emphasis. A new theory may propose being selective in both the emphasis on a particular theme or phase, including or excluding certain ones, and attending to any particular ones of these more than others, as is indicated by the particular context. For example, in a reworking of adolescence, the theme identity could still be salient - but perhaps be not the only theme, and perhaps not have the same sole emphasis.

Changed and added developmental themes. Since both society and developmental knowledge have changed, it is not surprising nor inappropriate to propose that there may be new concepts to add to Erikson's theory or key concepts that require modification. This is particularly applicable when considering the early childhood years. For example, the notion of self-regulation of emotion and resultant behavior has become the focus of much attention - and, given the prevalence of their inadequate development, the source of serious concern in recent years (e.g. VanderVen, 2008). An enhanced understanding of how they operate in childhood invites a reevaluation of Erikson's emphasis on autonomy and initiative.

\section{The Revised Eriksonian-Based Model for Development in the School-Age Years}

The Eriksonian conception of the developmental meaning of the school-age years within Erikson's work itself ... almost. Integrating the themes leads to a contemporary model that sustains Eriksonian structures and concepts.

Adding complexity and continuity, the model will include developmental themes at three different levels: primary, supportive, and contextual. A primary theme follows Erikson and posits that the particular phase of development can be expressed with a unitary construct. A supportive theme is one that contributes to the attainment of the primary theme, allowing it, even though unitary, to be in fact more complex, composed of multiple aspects. A contextual theme is one that was originally proposed by Erikson as a central task of a particular stage but recognized by him as being dealt with and developed in its own appropriate way in other stages. And therefore, while the primary theme and the supportive themes will be discussed explicitly. The contextual theme will be discussed in relation to other subthemes.

\section{The Primary Theme of the School Years: Competence}

Rather than maintain industry as the primary task of the school years, competence, following the influential work of Ann Masten and Douglas Coatsworth (1998) among others, is proposed. In his discussion of industry in The Life Cycle Revisited, Erikson himself lists competence as the "virtue" and "primary strength" of this period. Erikson's addition of these virtues as the outcomes of the original eight stages of development, demonstrates a broadening and deepening over time. In one of his last discussions of his life cycle theory, as it was called then (Erikson, 1982), industry was described as "competent mastery necessary to be experienced during the school years" (Erikson, 1982, p. 6). 
One might ask, "Why change competence for industry?" The reply is that, in light of the advanced understanding of developmental capacities ushered in by the last half century, a refined definition of industry is now needed. Competence is a more embracing concept than industry - significant as that attribute is. The term is current in today's developmental psychology literature. Competence means that a child is developing instrumental skill sets from both academic and multiple domains of childhood activities through a process of authoritative adult instruction, scaffolding, and experimentation. Both are crucial. Competence also means that the youngster is developing important social and emotional attributes necessary for functioning in the adolescent and adult world to follow. In these ways, competence is holistic and multidimensional, in accordance with the aforementioned principle of nonlinear dynamical systems theory.

The significance of competence is further highlighted by Eccles and Wigfield (2002), who call the human "basic needs for competence" (p. 112). Masten and Coatsworth (1998) suggest that being competent does not mean that the child is always happy, has a high self-esteem, and is without problems and issues. Thus a resilience rationale for the competence phase is central. Youngsters must be resilient with sufficient core of self as expressed in specific interests in what they are engaged in, along with the requisite developing skills needed for participation, to prepare for the demands of the succeeding phase. Thus it is proposed that competence be the focal developmental theme for the school-age years, as well as a significant supportive theme for all the phases of development throughout the life course.

Competence, as conceived herein, is crucial for successful emergence and transition into the next developmental phase, as proposed by VanderVen (2006): the middle school years. Given the incredible demands and normative temptations of that phase (e.g., puberty, the pressing desire for social acceptance, peer influence to engage in unhealthy or risky practices), as the child leaves the relative security of the elementary school years, a strong consolidation of the emotional, social, and behavioral strengths (along with activity and academic skills) that mark fully developed competence is needed.

\section{Supportive Themes}

Industry. Industry interestingly remains a crucial quality of the childhood period in general, from toddlerhood through adolescence and on into adulthood. Self-regulation, the salient task of the preschool years, pertains to a variety of attributes that enable a youngster to display self-control in the face of frustration and temptation. However, the notion of self-regulation seems to be less tied to task and learning performance than to emotional constraint and interactions with others in daily life.

Some early childhood educators such as Lilian Katz (1993) have considered the importance of developing dispositions related to work habits in early childhood, as a precursor to school readiness. Such habits include finishing what one 
has started, concentrating on a particular activity, and respecting boundaries inherent in the activity. Industry, like so many other Eriksonian concepts, should be considered a life long attribute, although its foundations begin in childhood. Indeed, the groundwork for industry is laid even before the school-age years, as suggested by the development of Katz's work habits or dispositions in the preschool years as necessary underpinnings of successful learning in the school-age child.

Following the understanding of the dynamics of resilience, (e.g., Masten \& Coatsworth, 1998) today the main developmental task of the school-age years should be viewed through the contribution of industrious behavior, that is, work habits and approaches to tasks, coupled with emotional self-regulation. This displays and supports competence. Erikson's original theme, in this context, relates more specifically to work habits, that is, behaviors as simple as reviewing and correcting work, evaluating a job to be sure it is done well and all components are completed, and getting underway in an energetic and planful way when there is a job to be done. This theme is a continuation of the notion of work habits, or dispositions in early childhood. For young children, dispositions or habits of mind include curiosity, intentionality, self-sufficiency, and the ability to self-organize. The self-esteem movement did not help with the development of work habits, in that shoddy work and minimal effort would come to be praised, thereby stopping attempts to improve one's approach to the task.

Engagement. Engagement, as presently conceived, is the mental energy necessary to become interested in and involved in the constructive tasks and activities that lead to competence. While engagement is often discussed with reference to adolescents in school (e.g., Bundick, 2011), this quality also applies to school-age children. Engagement is quite akin to the concept of dispositions mentioned before (Helm \& Katz, 2001). The relationship of engagement to industry is strong in that engagement in a defined and structured activity serves to promote industrious behavior.

Empathy. Empathy is the ability to recognize that others have feelings and sensitivities and affects the way one treats others. Empathy begins to develop in early childhood, a process which can be disrupted if there are difficulties in forming secure attachments. Empathy is a requirement for making and keeping friends, and given the importance of the peer group to school-age children who are taking the huge step from the family to the world of others, its significance is crucial. Those who have a strong capacity for empathy are more likely to engage in altruistic behavior and less likely to engage in bullying behavior. In fact, it has been proposed that the upsurge in bullying behavior has origins in disruptions in early attachment.

Self-Regulation. Self-regulation, the ability to control and modify oneself without suppressing one's own emotions, figures largely in the potential of school-age children for success. In recent years, as already mentioned, the concept of selfregulation has attained salience in the early childhood community with the recognition that to be prepared for school, preschool children must be able to control 
their emotions and behavior. Self-regulation includes the ability to recognize the emotions one is experiencing and includes the capacities to pay attention, solve social problems harmoniously, and to tolerate frustration without a strong behavioral response that requires external intervention.

In line with the intent to connect phases of development vertically, with flexible boundaries and transitions, self-regulation is viewed as a process beginning in earliest childhood with growing significance in the preschool skills and with high importance in the school years. It might be seen as a contributing and supportive factor in Erikson's industry, and ultimately, competence.

Developmental Trajectories. Anna Freud's still viable proposals of developmental lines-crucial tasks in specific domains that change or are "gradated" as a function of growth (Freud, 1965, p. 63) are applicable to this revision of Erikson's proposals on school age children. Making an adaptation based on the more current notion of developmental trajectories, the proposal here is to consider Erikson's universal developmental themes that are so well known, as development trajectories somewhat akin to Freud's developmental lines. They are also still considered current, although other developmental concepts such as those described as supportive themes are more recent and more directly tied into the particular phase of development. For the purposes of this model, the Eriksonian themes of identity and generativity will be considered.

Identity. Perhaps the most fundamental of all of Erikson's constructs, one must go beyond the association of identity with adolescence to acknowledge Erikson's own contention that identity formation begins early in life and continues throughout. For school-age youngsters preparing for middle school and adolescence, with the focus on developing competence, the relationship with identity is obvious. Their own awareness of what, when, and how they are acquiring new knowledge and skills that are of meaning and use in larger society, and also their content of these interests, will shape their growing and emerging sense of self, that is, their identity.

Generativity. The Eriksonian notion of generativity, essentially giving-and giving back - with a particular focus on leaving something positive behind for future generations, has a contemporary meaning important in the development of school-age children. If empathy is a newer indicator of positive development, then generativity is an underlying dynamic. Where school-age youth learn that there are ways that they can serve or give to others, and in a way that is meaningful (that is, makes a lasting impact), this not only encourages the further development of empathy, but also contributes to an overall sense of competence. Helping an older person, looking out for a younger child, teaching a skill to a younger child, caring for a pet, saving money to make a contribution-these are examples of how a school-age youth can be generative. One may not immediately see how such interactions may leave an identifiable legacy, but further thinking can indicate how it can occur. A simple action or interaction, bearing in mind the nonlinear dynamical 
systems concept of "sensitive dependence on initial conditions," a small action can have large effects over time. Of course school-age children can perform concrete tasks that leave something positive behind-a sustainable project such as a mural, to give one example. Also, the developmental groundwork of generativity (and development of competence) in the early years can contribute to the sense, when one is elderly, that one has lived one's life in a way that will benefit future generations.

\section{Counterpart Theme: Ineptness}

To follow the intent of representing the challenges and themes of school-age child development today in as much an Eriksonian vein as possible, one must consider the developmentally less favorable counterpart to the developmental themes. Perhaps the main characteristic of ineptness is an inability to fit in in some waythat is, to apply the supportive themes and the dynamic interactions between them to somehow become competent as described. When youth have a sense of being inept at whatever activity or life domain in which they are participating, that feeling may become internalized. The degree to which this occurs might vary with the degree of ineptness, the significance of and meaning to, the youth of this particular area, and the context, for instance, the degree to which it is valued. It should be stressed here that some sense of ineptness is not completely negative or a detriment to development- that one learns from one's failures or difficulties, as well as from one's successes and areas of comfort. Such learning can be a stimulus towards greater effort, developing new interests, and other positive outcomes.

\section{Subthemes}

To avoid misunderstanding, because the themes described below are not directly supportive of positive development as are those for competence, they will be referred to as subthemes of ineptness. This label was chosen to indicate some of the secondary (albeit still important) outcomes of ineptness in the tasks of competence. These are presented in ascending order of developmental seriousness, that is, the degree to which they are a negative consequence.

Discouragement. When youth are not able to marshal the developmental attributes into the learning and social world of the school years, inevitably they receive feedback. Feeling discouraged does not always bode poorly for overall development, if the youth are lucky enough to have supportive adults and other contextual factors available, who can encourage them in a variety of ways to accept themselves, both strengths and weaknesses, despite the failure, to try again, to practice the requisite skills, and to recognize and develop other areas for knowledge and skill development.

Withdrawal. Withdrawal is in a sense a counterpart of engagement. When an overall sense of ineptness is experienced, in the absence of supports and alternative sources for a sense of competence, the greater danger is in withdrawal. In such a situation, that the youth withdraws their emotional energy and interest, without 
refocusing and investing it into something else where they perhaps may have a greater chance at success.

Sadness. With continued input into a growing sense of ineptness, withdrawal may slide into sadness, a more pervasive effect than discouragement or withdraw$\mathrm{al}$, and with more serious implications. With this deep negative feeling, there is less likelihood that without a careful assessment, planned intervention, and monitoring for effective results, that the youth will emerge from the phase of competence and ineptness emotionally unscathed.

Anger. While there is a danger of oversimplifying, a negative counterpart of a sense of ineptness can be anger. As with many emotions, all anger is not destructive: It can be justifiable and can goad its holder into constructive action. At the same time, unsupportive responses of others to ineptness create resentment and anger, and may contribute to the emergence of bullying behavior or other kinds of acting out.

\section{Implications for Practice}

How then might this model be translated into specific practices in the various settings holding school-age youngsters? Following are some general and brief considerations:

Schools. In order not only to promote academic competence but also to promote overall developmental competence, along with the areas that support it, schools need to ensure a comprehensive approach to educating the whole child. Indeed the main responsibility of schools is to develop academic knowledge and skills. However, teachers, school leaders, and educational policy makers need to realize that the amputation of activities and pedagogies that provide opportunities for both faculty and students to interact informally, may have a paradoxical and decidedly undesirable outcome. Rather than developing academic competence and fostering academic achievement, there is a risk of lowering it by increasing disengagement, making youth feel there is nothing in school they can attach to, and increasing asocial behavior. Schools must be places where everybody feels safe, both physically and emotionally, devoid of the threat of bullying. Such a school culture and total program would provide opportunity for joint collaboration in meaningful projects such as community service, and opportunity for all youth to discover areas in which they have the potential to develop competence. For teachers and administrators in schools to maintain discipline does not mean that they cannot be relational within their primary intent as educators. Being relational provides a context for positive relationships, characterized by the attention, interest, and encouragement that school-age children need to thrive academically, socially, and emotionally.

After School. It is the special province of after-school programs to provide experience in the domains of activity that for generations have appropriately occupied out-of-school time. These include arts, crafts, games, sports, drama, music, 
and movement. More contemporary forms are also appropriate, such as computer skills, video production, and robotics. It is crucial that after-school programs provide truly authoritative and authentic activities. These are knowledge- and skillbased, and play a fundamental role in developing competence, industry, and engagement.

After-school programs also enable staff to provide essential relational ingredients that help develop empathy and prosocial skills. While school teachers can and should be relational, the somewhat more informal context of after-school programs enables staff to be more flexible, informal, and personal within appropriate developmental boundaries. Homework has a place in after-school programs especially for older children whose homework loads are often heavy, but only when properly handled and offered not to the exclusion of rich activity programs. These can support those children who need special assistance with their academic work. Some children will want to do it, some will need to do it, and all should have the option to choose. At the same time, homework must not be a mere extension of the academic school day and should not replace the primary focus on activities.

Families. Of course all families, no matter what their structure, need to provide a fundamentally caring, stimulating, and nurturing environment with sound parenting and caregiving practices. The focus should be less on happiness (e.g., Gottlieb, 2001) and self-esteem, and more on those practices that contribute to the development of competence, self-regulation (industry), and engagement. This is a tremendous challenge in this age where there seem to be more helicopter and absent parents rather than authoritative parents, reflecting back to Baumrind's (1967) important research on effective parenting. Authoritative parents offer crucial attachment figures, stability, and support while simultaneously encouraging their children to develop discipline, to strive for what they want rather than have it given to them without effort while differentiating between wants and needs, which of course should be met.

\section{Conclusion}

The significance of a positive outcome of the school-age years cannot be overemphasized. If there is a positive consolidation of the themes already described, one can hypothesize that youth will enter the challenging middle school years with ego strength — which was Erikson's quite appropriate term to refer to a strong consolidation of skills and outlook. The youth must have sufficiently developed interests and skills in the activity world to be able to find a place among their peers, and to resist the unhealthy temptations of premature sexual behavior and substance consumption that can serve as a developmental derailment. To prevent slippage into an exclusionary and bullying mode of behavior, youth must bring up from the preceding phases of development an empathic ability that can provide both the strength to resist peer pressure to mistreat and reject others, and instead help to channel the youth's energy toward positive forms of belonging and prosocial behavior. 
In his brilliance, Erikson himself anticipated the movement towards competence as he himself moved beyond Industry vs. Inferiority with the "psychosocial strength" (Erikson, 1964, 1982) of competence, superseding the seemingly dichotomous themes and emerging as a positive outcome of the school years. Erikson had described competence as a virtue: "Competence, then, is the free exercise of dexterity and intelligence in the completion of tasks, unimpaired by infantile inferiority" (1964, p. 124). Inferiority seems to be much less well-described than both industry and competence. It is described in Childhood and Society (1950) as "a sense of inadequacy and inferiority. If he despairs of his tools and skills or of his status among his tool partners, his ego boundaries suffer and he abandons hope for the ability to identify early with others who apply themselves to the same general section of the tool world" (1950, p. 227).

Erikson anticipated a number of the areas that eventually became more widely articulated and described as necessary for a contemporary developmental or life course theory, such as continuity, nonlinearity, and adaptation to changes in the times. So this paper has had a rather circuitous journey with the enlightening discovery that, on re-reading Erikson carefully, he actually anticipated future trends in developmental theory and research through his formulations and adaptations of the earlier works in the later ones. Particularly presciently, he talked about strengths before the positive psychology and resilience concepts became so prominent in modern-day psychology. His constant revisions of his own concepts and theories over the years provides a rationale for the continued reexamination of his monumental work.

So, while Erikson's life cycle theory still needs to be reconceptualized in the contemporary context, nonetheless Erikson's ideas still contribute to his own perpetuity, leading to a sense of comfort that reworking him, so to speak, actually enables his work to remain deservedly in the forefront.

\section{References}

Baumrind, D. (1967). Child care practices anteceding three patterns of preschool behavior. Genetic Psychology Monographs, 75(1), 43-88.

Baumeister, R., Campbell, J., Krueger, J., \& Vohs, K. (2003, May). Does high self-esteem cause better performance, interpersonal success, happiness or healthier lifestyles? Psychological science in the public interest, 4(1), 1-44.

Bronfenbrenner, U. (1977). Toward an experimental ecology of human development. American Psychologist (32), 513-531.

Bundick, M. (2011). Extracurricular activities, positive youth development, and the role of meaningfulness of engagement. Journal of Positive Psychology, 6, 57-74. 
Eccles, J., \& Wigfield, A. (2002) Motivational beliefs, values and goals. Annual Review of Psychology, 53:1, 9-32.

Erikson, E. (1950). Childhood and society. New York, NY: W. W. Norton.

Erikson, E. (1964). Human strength and the cycle of generations and identity and uprootedness in its time. In Erikson, E. Insight and responsibility. New York, NY: W. W. Norton.

Erikson, E. (1982). The life cycle completed. New York, NY: W. W. Norton.

Freud, A. (1965). Normality and pathology in childhood. New York, NY: International Universities Press.

Galatzer-Levy, R. (2004). Chaotic possibilities: Toward a new model of development. International Journal of Psychoanalysis, 85, 419-442.

Gottlieb, L. (2011). How to land your kid in therapy. Why the obsession with our kids' happiness may be dooming them to unhappy adulthoods. The Atlantic.

Helm, J., \& Katz, L. (2001). Young investigators: The project approach in the early years. New York, NY: Columbia University Teachers College Press.

Katz, L. (1993). Dispositions as educational goals. Urbana, IL: ERIC Clearinghouse on Early Childhood Education.

Lareau, A. (2003). Unequal childhoods: Class, race and family life. Berkeley and Los Angeles, CA: University of California Press.

Levine, S. (1995). Adult growth in schools: The promise of professional development. Braintree, MA: Association of Independent Schools in New England.

Mahoney, J., Harris, A., \& Eccles, J. (2006). Organized activity participation, positive youth development and the "over-scheduling hypothesis." Social Policy Report. Ann Arbor, MI: Society for Research in Child Development.

Masten, A., \& Coatsworth, D. (1998). The development of competence in favorable and unfavorable environments. American Psychologist.

Scales, S., Sesma, A., \& Bolstrom, B. (2004). Coming into their own: How developmental assets promote positive growth in middle childhood. Minneapolis, MN: Search Institute. 
VanderVen, K. (2005). The developmental life span theory of Erik Erikson: A linear or dynamical systems model. Presented at Winter Chaos Conference of the Blueberry Brain Institute, Springfield College, MA.

VanderVen, K. (2006). The twenty-first century Erikson. Book proposal. Unpublished manuscript.

VanderVen, K. (1996). Towards socialization and harmonious cross-cultural relationships: Integrating cultural universals and cultural specifics through the activities of "The culture of childhood." Paper presented at Harvard Graduate School of Education.

VanderVen, K. (2008). Promoting positive development in early childhood: Building blocks for a successful start. New York, NY: Springer.

Werner, E., \& Smith, R. (1992). Overcoming the odds. High risk children from birth to adulthood. Ithaca, NY: Cornell University Press.

*Special acknowledgement to:

Dr. Matthew Bundick for his review and commentary of this paper, although the author assumes complete responsibility for its contents.

Dr. Andrew Schneider-Muñoz for his overall support and encouragement.

**This paper contains material to be included in the forthcoming book The TwentyFirst Century Erikson: A New Life Course Theory for a Changing World. 